\title{
DELAMINATED CELLS FOR NANO-ENABLED INKJET PRINTABILITY
}

\author{
ARNIZA GHAZALI, ${ }^{*}$ NUR HAFFIZAH AZHAR, ${ }^{*}$ SHAHROM MAHMUD, ${ }^{* *}$ MOHAMMAD FAUZUL \\ AZIM MOHD KHAIRUDIN, ${ }^{* * *}$ ISHAK AHMAD,${ }^{* * *}$ MOHD RAFATULLAH,${ }^{* * * *}$ MUHAMMAD AL \\ AMIN ZAINI $^{* * * * *}$ and YUSHAMDAN YUSOF ${ }^{* *}$ \\ "Division of Bioresource Technology (BRT), School of Industrial Technology, \\ Universiti Sains Malaysia, 11800 USM, Penang, Malaysia \\ **NanoOptoelectronic Research and Technology (NOR) Laboratory, School of Physics, \\ Universiti Sains Malaysia, 11800 USM, Penang, Malaysia \\ *** Department of Chemistry, Faculty of Science and Technology, Universiti Kebangsaan Malaysia, 43600 \\ Bandar Baru Bangi, Selangor, Malaysia \\ ${ }^{* * * * *}$ Division of Environmental Technology (EnTech), School of Industrial Technology, \\ Universiti Sains Malaysia, 11800 USM, Penang, Malaysia \\ ***** Dainippon Ink and Chemicals (M) Sdn Bhd, HICOM Industrial Park, \\ 40400 Shah Alam, Selangor, Malaysia \\ \Corresponding author: A. Ghazali,arniza@usm.my
}

Received August 19, 2021

\begin{abstract}
Nanometer scale cells delaminated from oil palm fruit bunch (EFB) microfiber cell walls were coated on commercial A4 and laboratory sheets prepared from virgin fibers. High-resolution transmission electron microscopy (HRTEM) revealed the cells as translucent laminae of fibrils (TRX) bound together in a $5 \mathrm{~nm}$ to $100 \mathrm{~nm}$ thick web with dendritic edges. Coating of TRX onto the commercial A4 paper improved inkjet printability by up to $80 \%$. The nano-enabled printability occurred as a summed effect of TRX forming (1) a canopy on or "loose-masking" of the protruding inorganic fillers, (2) capillary bridging of micro-voids formed by TRX fibrillary ends, (3) partial bridging of microgaps, (4) masking of the fiber surface, and (5) nano-grip arising from dendritic ends slipping into the micro-voids. The TRX-coated virgin pulp network revealed improved nano-enabled coverage by significantly reducing the stray and by print uniformity. The results provided an insight into the possibility of interfacing TRX with the paper surface for an improved inkjet print and economy through high-precision printing, also providing a pleasurable reading experience.
\end{abstract}

Keywords: paper coat, translucent cells, precision printing, printability, bleed, bio-coat

\section{INTRODUCTION}

The Covid-19 pandemic has reset the trends in the supply chain and the demand pattern for paper products. The change even leads to several breakthroughs in reengineering paper surfaces to practical use as Covid-19 protective gear. Indeed, scientific detailing of papers has extended paper applications beyond the conventional norm. Paper diagnostics, such as a microfluidic strip for a blood type test, ${ }^{1,2}$ paper-based supercapacitors, ${ }^{3}$ and the use of paper as a capillary electrophoretic medium in separation science manifest the versatile applications of paper. Despite the modern functions, the traditional role of paper prevails partly due its tangibility as a communication medium, comfort, radiation-free nature, flexibility, affordability, zero need for electrification, flexible conversion to other products, such as packaging, and the broad market.

Even spread of ink and elimination of image astigmatic effects are a mandatory factor for strain-free, pleasurable reading. In inkjet print, this is overcome by reducing the dendritic and uneven ink spread, while in laser print, precise landing and fusion of toner, which is visually evident as toner spread-and-stray reduction, are factors requiring control. In the latter, surface charge distribution on papers is influential in preventing a blotchy print image that reduces reading pleasure. Whether for intricate reading or 
glancing at labels on packages, detailing the paper surface is required to achieve a desirable outcome and printing economy.

Excellent printability is often associated with the smoothness of the paper surface, and in practice, such inorganic fillers as amorphous silica, ${ }^{4}$ clay, titanium dioxide, alumina, talc ${ }^{4,5,6,7}$ and calcium carbonate ${ }^{8,9}$ of various scales and shapes are added to enhance the optical properties of papers. ${ }^{10}$ Calcium carbonate as a cheaper mineral has been in use for many decades as an additive to reduce the use of fibers, improve smoothness ${ }^{9}$ and positively influence printability. ${ }^{8}$ The use of fossilized granulated calcium carbonate (GCC) in the paper, adhesives, and paint industries competes with the demand from such critical industries as the food, pharmaceutical and construction industries ${ }^{11,12}$ (Fig. 1). The demand is fulfilled by converting the waste from the construction industry into useful feedstock for the synthetic calcium carbonate production serving as a substitute ${ }^{13}$ known today as PCC or the precipitated calcium carbonate.

To overcome the poor retention of calcium carbonate, ${ }^{8}$ and its interference in inter-fiber hydrogen bonding, ${ }^{9}$ earlier efforts focused on the less popular idea of precipitating calcium carbonate inside the fiber lumen by injecting lime solution and precipitating calcium carbonate in situ. The process, however, extended the papermaking fiber preparation process. ${ }^{10}$ Later in the calcium carbonate research timeline, the approach was more inclined towards modifying filler shape and surface chemistry. Chen and coworkers, for instance, attempted substituting the conventional precipitated calcium carbonate (PCC) to the use of calcium carbonate whiskers (CCW) and found an encouraging effect of CCW shape and size in reducing the negative impact of calcium carbonate on inter-fiber hydrogen bonds. ${ }^{8}$ The underlying occupational and process safety risks regarding the manufacturing and application of CCW at the papermaking line remain a critical factor to consider in the manufacturing decision. Even more profound is the risk related to $\mathrm{CCW}$ or PCC particles having a diameter below $100 \mathrm{~nm}$, known to possess an extraordinary size-dependent reactivity. ${ }^{14,15}$ Beyond the established federal regulatory identification of $\mathrm{CaCO}_{3}$ as a potential irritant, ${ }^{16,17}$ nanoparticle $\mathrm{CaCO}_{3}$ was found to impose moderate to high occupational risks ${ }^{15}$ and is subject to Occupational Safety and Health Administration (OSHA) permissible exposure limit. $^{18}$

Silica shelling ${ }^{19}$ of calcium carbonate was reported by Morsy and her research team to improve the filler retention and optical properties of paper. Similar improvements were achieved by immobilizing the mineral fillers with cellulose nanofibrils ${ }^{20}$ and cellulose ester. ${ }^{9}$ However, the application practicality of the $\mathrm{SiO}_{2} / \mathrm{CaCO}_{3}$ coreshell nanocomposite ${ }^{19}$ and other immobilization approaches depend on its overall economy relative to the conventional practices. The tendency of the macro and nanoscale fillers to escape the papermaking wires, moreover, raises the filler's potential as an airborne pollutant ${ }^{15,19}$ identified as a respiratory hazard..$^{15,21-24}$

Besides, the migration of nanoparticles from paper to $\operatorname{food}^{25}$ mirrors the pathway of the ingestion hazard directed to human health. ${ }^{18,26}$ In addition to the less spoken genotoxicity, to some extent, inorganic fillers also hamper fiber network strengths. ${ }^{4,27,28}$ The setbacks are overcome by applying starch, ${ }^{29}$ and they are considered negligible due to the capital savings brought about by the $8 \%$ to $30 \%$ filler-for-fiber substitution.

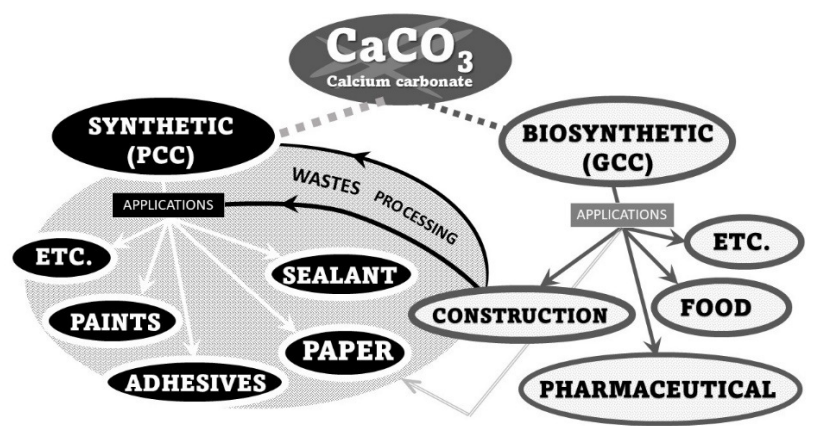

Figure 1: Competing uses of natural (biosynthetic) calcium carbonate, prompting an effort to process the waste from the critical industry for use in other sectors, such as the paper and paint industries 


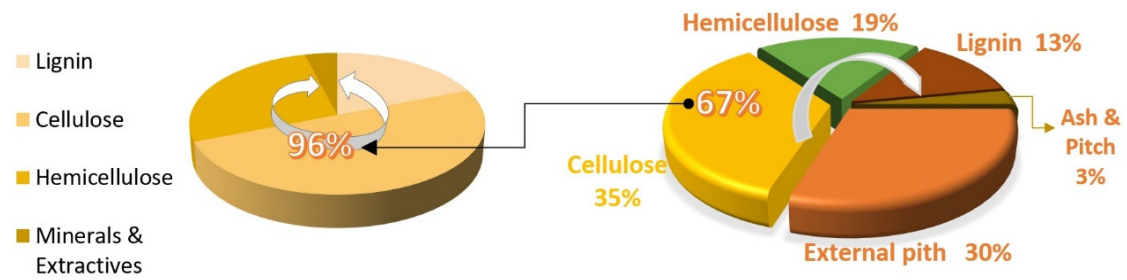

Figure 2: Composition of EFB vascular bundles devoid of 30\% external pith (left), and comprising it (right)

Besides limiting paper recyclability, ${ }^{20}$ which disrupts the circular economy nature of the papermaking industry, ${ }^{28}$ dusting $^{9}$ and contamination of printing presses and copiers ${ }^{4}$ are among the challenges to the printing section. With varying focus areas, studies seeking solutions to the situation have been on the rise. Barhoum and his team engineered the surface of selected nanofillers for facile high-end industrial-scale applications. ${ }^{30}$ Shen and Qian demonstrated the surface filling concept and invited readers to ponder the untold challenges. ${ }^{29}$ Insights into the use of organic fillers developed in the United States, Korea, and Finland were part of the continuous search for alternative materials to better align towards sustainability.

Presented herein is the outcome of interfacing the paper surface with the delaminated nonrecyclable ${ }^{31}$ microfibers from an industrial waste, the oil palm empty fruit bunch (EFB) - the biomass that allows $63 \%$ capital-saving in the papermaking process by EFB-for-wood fibers substitution. EFB is the residue from the palm oil milling aimed within the United Nation's Sustainable Development Goal (SDG) 2 for curbing food shortage and hunger. ${ }^{32-34}$ Thailand, Indonesia and Malaysia plantations strive to ensure healthy ecological practices by adhering to the standards set by the United Nations through the Roundtable on Sustainable Palm Oil (RSPO) ${ }^{34}$ However, the industry leaves behind fibrous biomass, which is studied for use as feedstock for product development, to rule out such ecologically destructive management as open-burning.

Delamination of the microfiber was engendered by mechanical action at the perhydroxyl or dioxydanal reacted sites, where the inter-cell layers are weakened. As a result of extensive milling, the microfibers uniquely liberate delaminated cells amongst the P200 mass $^{35}$ registered with a trademark, as TRX- cells ${ }^{\mathrm{TM}}$ or TRX in short. With such a mechanism, the process offers a $96 \%$ yield by maximizing the $67 \%$ non-pithy mass of the fresh fruit bunch waste, as shown in Figure 2.

The current study rerouted the EFB microfibers from adding to the world 0.6 billion tonne $^{36}$ paper and paperboard types of landfill wastes to a valuable commodity. With the perspective of an improved fate, this study explores the nature and the functional mechanisms of TRX when applied to selected paper surfaces to impact printability.

\section{EXPERIMENTAL}

\section{Preparation of paper sheets}

Virgin pulp from oil palm biomass (empty fruit bunches, EFB, and frond petiole) was produced via 40 to 120 minutes pre-treatment of the biomass in alkaline peroxide (Merck Schubart, Germany; 30\% hydrogen peroxide premixed with ACS reagent sodium hydroxide) at $70{ }^{\circ} \mathrm{C}$. Mechanical refining at 54.95 $\mathrm{kWh} / \mathrm{t}$ specific refining energy was performed using the Andritz Sprout Bauer refiner to shear the biomass into pulp. Laboratory handsheets were formed from the fibrous mass. Of these, several webs of virgin fibers were selected for the printability test.

TAPPI Standard Method ${ }^{37}$ T211 om-02 was adopted to confirm the $15 \%$ of inorganics contained in the 80 -gsm commercial A4 paper. The pulp suspension of the commercial paper was disintegrated and sedimented. Elemental analysis of the sediment was performed using a Leo Supra 50VP Carl Zeiss Scanning Electron Microscope (SEM), interfaced with Oxford X-MaxN $80 \mathrm{~mm}^{2}$ with INCA software.

\section{Delaminated cells: characterisation and coating}

The microfibers obtained from the oil palm EFB were deconstructed by the delamination of the primary and secondary cell layers to yield translucent cells (TRX-cells $^{\mathrm{TM}}$, interchangeably denoted as TRX-cells, TRX coat, and TRX coating depending on the context). Delamination, performed at 10,000 mechanical milling revolutions using a PFI mill, produced a mass of fines subsequently stored as suspension. For the dip-coating purpose, a clear, 
diluted $(0.04 \% \mathrm{w} / \mathrm{v})$ suspension of the cells was made, and a smear with it was prepared to confirm the cells' presence against the control experiment. The cells suspension was continuously stirred in a stainless-steel tray, while dip-coating the papers by sliding in one curved horizontal direction. Dip-coated papers were left to stand at $23-25{ }^{\circ} \mathrm{C}$ (without couching, pressing, and clamping as customarily applied in the laboratory sheet preparation procedure ${ }^{38}$ for 24 hours before the printability test and further analyses.

\section{Advanced microscopy of TRX cells}

The 3D image of the dried smear of coating cells was acquired using a Leo Supra 50VP Carl Zeiss Scanning Electron Microscope (SEM) for verifying the presence of TRX-cells in the clear suspension. The smear was compared with the dried blank smear of the distilled water used to suspend the cells. Highresolution FEI TECNAI G2 Transmission Electron Microscopy (HRTEM) analysis was performed on the cells by mounting on copper and lacey carbon grids to enhance the chances of visualization and elemental mapping through Oxford X-MaxN $80 \mathrm{~mm}^{2}$ with INCA software. The difficulty in distinguishing between the carbonaceous sample holder and the coating cells was overcome by prolonged electron bombardment, which caused the rupturing of the cells. The Bruker Dimension Edge Atomic Force Microscopic analysis of the coated and uncoated papers was run to estimate the surface roughness of the substrates.

\section{Contact angle measurement}

A Holmarc Contact Angle meter HO-IAD-CAMOIB, a research facility at Universiti Kebangsaan Malaysia, was employed to determine the fluid contact angle of the paper substrate via the sessile drop method. The instrument came with a high-performance aberration-corrected imaging lens interfaced with the CMOS video system, which enabled the recording of the fluid evolution profile at ambient temperature. A Sony IMX576 Exmor RS (24 megapixels, f/1.7 aperture) recorded the slow-motion fluid-substrate contact.

\section{Printability test}

Papers of sufficient brightness were selected for printability tests to contrast the printed area and background. These were commercial A4 and various $60 \mathrm{gsm}$ laboratory handsheets from virgin pulp. Of these papers, there were sheets produced from coarser fibers from oil palm petiole (B). The metal-pressed side of B was analyzed separately, and this is labelled C. The paper from the mill waste fruit fibers that contained redeposited leaching material due to a prolonged reaction in alkaline peroxide is denoted $\mathrm{D}$ or "pitch-deposited" surface. A comparison was made with the pitch-free papers (E) produced under an optimal alkaline peroxide reaction duration from the same biomass.
Printability was assessed for two parameters: coverage and stray, which affect the printing economy, from printer maintenance to ink expenditure. While coverage captures the landing of the print element on the programmed sites, stray estimates ink bleed or spread, outlying the primary region. An Olympus UTVO.5XC-3 Xcam microscope provided the crosssectional views for examining ink and toner penetration depths and other related effects. As reflected by the scatter values of print coverage, print uniformity, which is the principal rationale for surface engineering, ${ }^{38}$ was also examined.

Water-based inkjet (Canon Pixma E410; fine Cartridge PG-47; 1-5 mPa.s viscosity) prints were made on the studied substrates, including the commercial A4, while LBP6030 Monochrome Resolution (2400x600 dpi), magnetic spherical, MS dry-type (electrophotographic toner) laserjet prints were made on commercial A4 as a benchmark of market accepted print quality. All prints were made using the same image. Printed areas were examined under a portable solid-state microscope, and print coverage, bleed and stray were evaluated with the superimposed digital grid. Scores for each printed grid were given per a prefixed halftone intensity scheme. Print coverage values were derived from Equation 1 for the percentage of A4 printability and Equation 2 for print coverage relative to commercial A4. Setting the commercial A4 paper as a benchmark, the total printed grid corresponding to A4 was set as the denominator.

A4 Print Coverage $=[($ Printed grid $) /$ Total grid Full Intensity] x 100

Print Coverage $=[($ Printed grid $) /$ Printed Grid for Commercial A4] x 100

Mann-Whitney's non-parametric statistical significance test was performed using Minitab19 on the basis that none of the acquired data was regarded as an outlier and thus taken in their entirety for statistical analysis to derive print uniformity values.

\section{RESULTS AND DISCUSSION Benchmarking the printability of commercial A4}

Laser print is recognized for its sharp and water-resistant prints due to the dry blend of plastic micro-particles, glass beads, carbon black, and color complex contained in laser toner particles. ${ }^{39}$ Through low magnification (x52) lenses, the sharper resultant laser prints arising from the $98.80 \pm 5.88 \%$ coverage (Fig. 3a) lies mainly on the surface $(8-40 \mu \mathrm{m}$ penetration, Fig. $3 c$ ), explaining the detachability of laser toner when inorganic filler percentage is high. The varying toner fusion depth may imply the $15 \%$ calcium carbonate filler distribution in the substrate. 
In contrast to laserjet varying toner infusion depth, the $74.6 \pm 20.8 \%$ print coverage for inkjet print (Fig. 3b) shows a more consistent $37.4 \mu \mathrm{m}$ depth, exceeding $50 \%$ of the paper cross-section (Fig. 3d), spreading vertically into the substrate by capillary action. The consistently deeper penetration risks ink showing up overleaf. While the horizontal capillary action of ink in the waterbased ink formulation (Fig. 3b) is standard in inkjet print, stray refers to the spread of toner particles apparent as pin-point dots beyond the primary print region, which is bizarre in inkjet print. Stray, derived from the guidelines set in the ISO/IEC 2017 image quality attribute for inkjet print, ${ }^{40}$ was used as a scientific metric due to its effect on print cleanliness. In voluminous printing, such defect may pose an ensuing cost over time analogous to high substrate absorbency, causing higher ink consumption. ${ }^{41}$

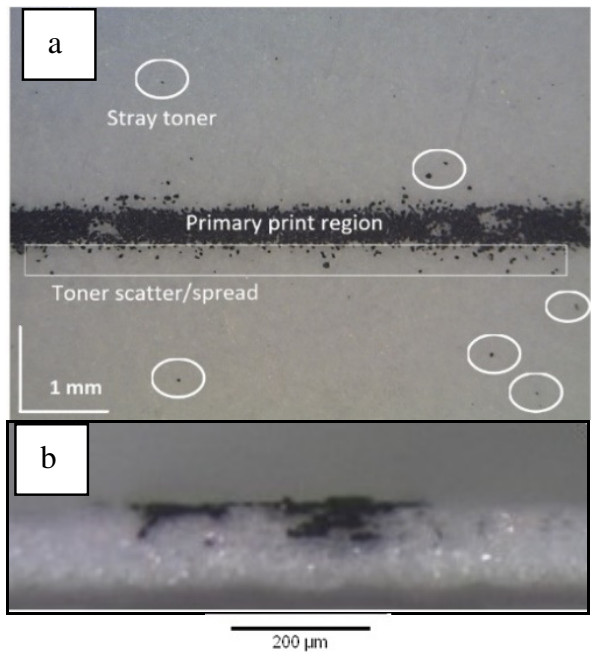

\section{Quantitative assessment of prints}

Approximately 50\% reduction in inkjet stray is detected consistently across the substrate (Fig. 4). The maximum stray observed for sample $\mathrm{C}$ (sheet surface pressed against metal plate) suggests slipping effects of ink upon contact with a leveled fiber surface, which was fixed by TRX cells coating. Commercial A4 (A) shows a statistically significant reduction of $50 \pm 3 \%$ in the stray of inkjet prints for TRX-coated paper.

In terms of data precision, stray inkjet improved with TRX coatings. With the exception of the leveled fiber surface (Sample C, Fig. 4), other substrates show consistently more precise stray data implied by the attenuated standard error $(\sigma)$ ranging from 0.06 to 0.96 (cf. before coating, $0.58-2.31$ ). The poor uniformity of sample $\mathrm{C}$ suggests the lower possibility for TRX to clasp to the leveled fibrous substrate during coating.

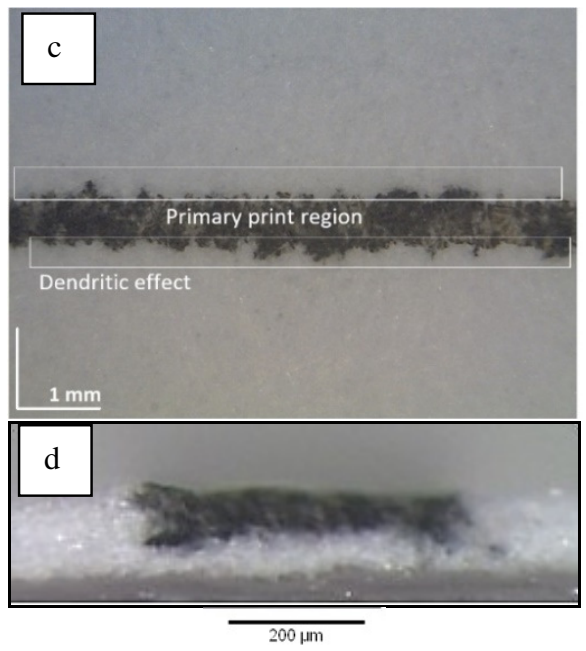

Figure 3: Print for commercial A4 showing (a) the top view of laser toner particles spread, its (b) cross-sectional view tangential to the printed area and (c) inkjet print top view and its (d) ink penetration depth

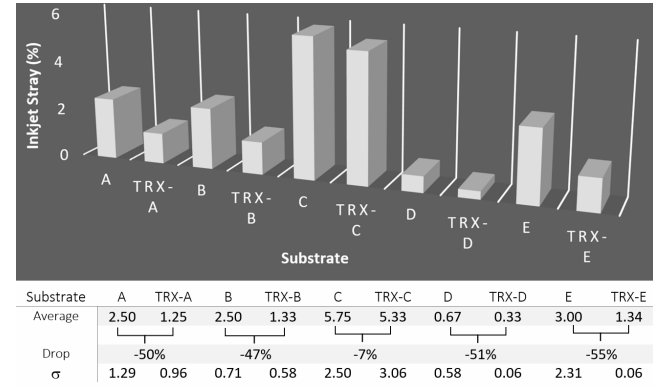

Figure 4: Effects of TRX on inkjet stray for various substrates

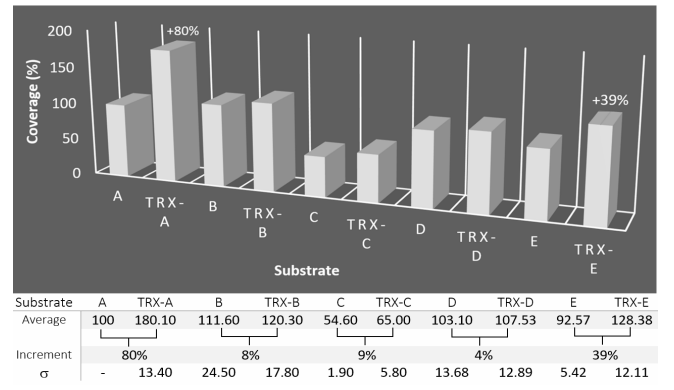

Figure 5: Inkjet print coverage with and without TRX coating 


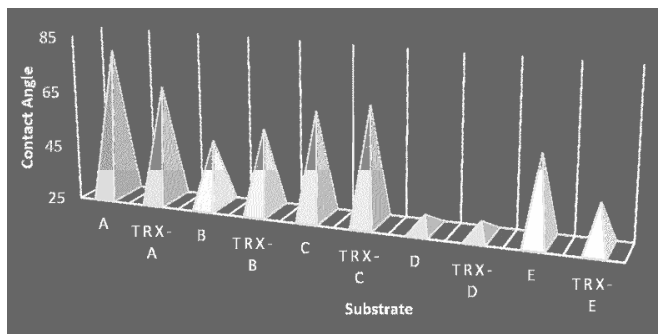

Figure 6: Relative hydrophilicity of substrates for inkjet print

Also of statistical significance is the $39 \%$ improvement in inkjet coverage observed in the TRX-coated pitch-free paper (E). These outcomes imply better control of fiber-ink interaction, arising from the effects of TRX on a fiber network, in the A4 case, in masking the $\mathrm{CaCO}_{3}$ fillers, for $\mathrm{E}$, in masking the pitch deposited on the substrate. In a similar vein, the reduction in contact angle (Fig. 6) for samples A and E attests consistently to the improved TRX coated surface affinity to the water-based ink.

Figure 4 and Figure 5 manifest the complementary values between coverage and stray, confirming that good coverage and reduced stray, which are characteristics of precision printing, are the correlated factors for print economy.

\section{Aqueous effect on leveled fiber network}

The unique effect of leveling the surface of the coarse paper (via pressing against a metal surface) manifests in the stray (Fig. 4) and coverage (Fig. $5)$. From the coverage value, flattening the coarse paper surface reduced inkjet printability from $112 \%$ to $55 \%$ (Sample B cf. C in Fig. 5), demonstrating that smoothing would not necessarily render a desirable outcome, but requires surface-substrate compatibility. ${ }^{38,42-44}$

Figure 7 presents the substantial ink discontinuity (Fig. 7a) resolving to a better continuum of PG47 Canon inkjet (7b). While capillary effects were only vivid in the directions of the fiber bundles, the captured irregularity in ink intensity only stemmed from the higher tendency of the colorant to concentrate in the crevices of the protruding surface.

Considering the variability of pore sizes, analogous to the micro-to-nano canal transition between uncoated and TRX-coated surfaces, the Lucas-Washburn capillary fluid flow model ${ }^{45}$ proposed by Cummins and team may provide a relevant explanation. In this regard, the better ink coverage of TRX coated paper (Fig. 7b) is attributable to the tendency of the fluid to travel further into the micro-voids, but halted the PG47 ink particles - at the smaller voids. Vertical permeation of ink was then rerouted to the surface nano-canals of the TRX and improved ink coverage, continuity, and bleed. The flow control mechanism demonstrates the potential of TRX in preventing the print from appearing overleaf, likely through complex imbibition dynamics ${ }^{45}$ of the cell.

The masking effect of TRX cells balances the possible effects of substrate swelling and network perturbation from rewetting by the aqueous TRX suspension. Atomic Force Microscopic (AFM) examination of sites with outstanding printability reveals a reduction in microscale surface roughness (from $0.193 \mathrm{~mm}$ to $0.134 \mathrm{~mm}$ after coating), plausibly caused by masking of TRXcells on the fibrous substrate. However, the 2D profile from the z-direction (top view) shows an increase in the nanoscale roughness from $510 \mathrm{~nm}$ at origin to $580 \mathrm{~nm}$ for TRX-coated substrate, indicating TRX possible folding and agglomeration as the cells landed atop the substrate (Fig. 7d). A similar example of folded TRX structure posing a unique ink flow control effect is shown in Figure 8.

Approximately $14 \%$ to $50 \%$ increments in the nanoscale roughness were detectable from sites portraying an improved printability, and these are associated with the sample coated with TRX cells. The increased surface roughness, which led to increased print quality, coincides with the industrial guideline g2,43 on the personalized coating formulations by the paper's variations. While the immense surface chemistry underpinning the enhanced selectivity is an aspect to be continuously explored, the outcome of TRX coating is further scrutinized to attest to the coating mechanisms. 

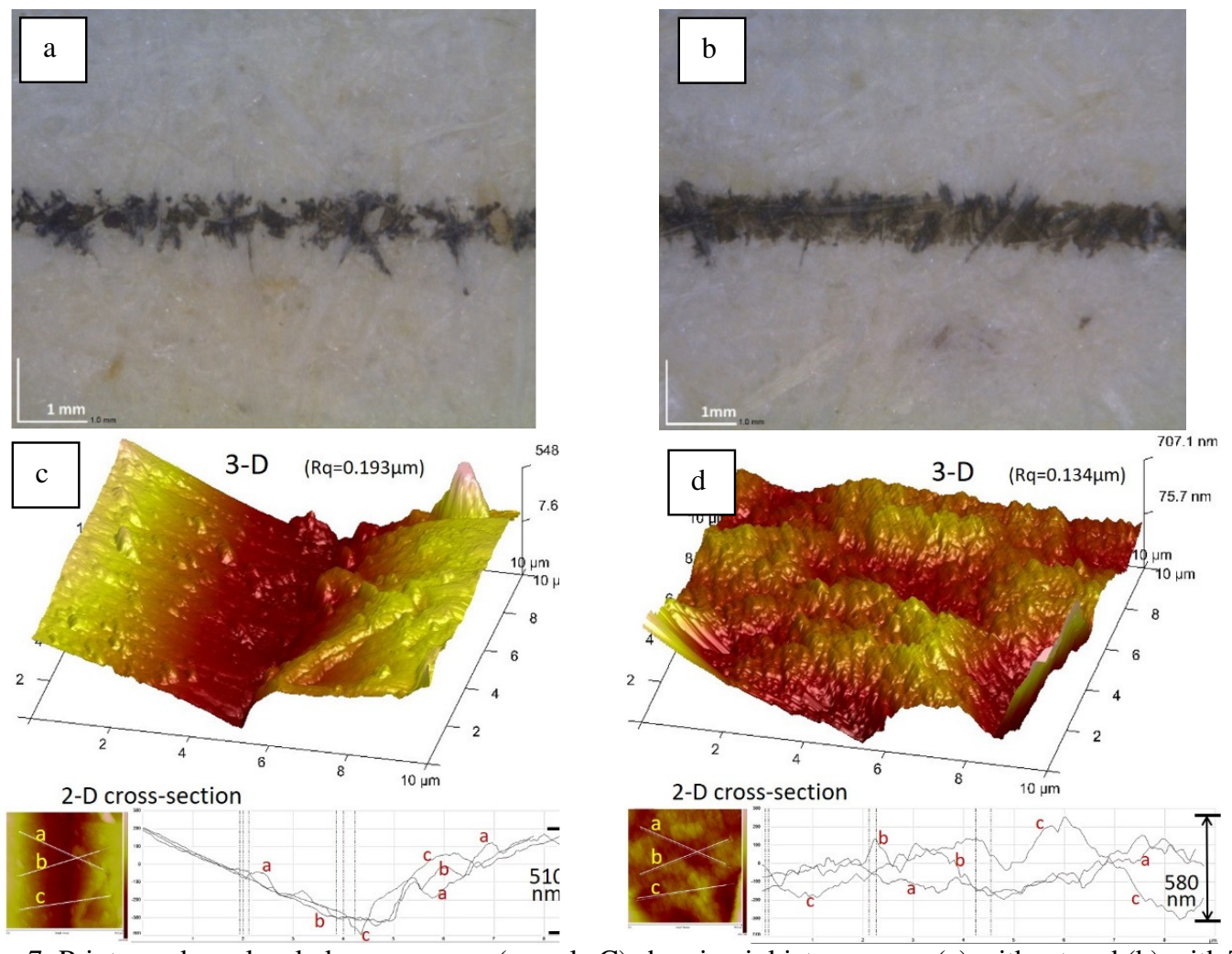

Figure 7: Prints made on leveled coarse paper (sample C) showing inkjet coverage (a) without and (b) with TRX coatings. AFM of (c) metal-flatten paper surface and (d) TRX coated leveled paper surface

\section{Mechanisms of precision printing}

The varying printability outcome suggests a specific pattern of ink-TRX-substrate interaction. The close-up analysis of the TRX-coated surface of virgin pulp and A4 paper showing significant enhancement in printability is discussed.

\section{TRX-virgin pulp interaction}

Folded and tangled TRX-cells (Figs. 8c and $8 \mathrm{~d}$, respectively) form bordered landing sites that restrict ink flow. As inkjet systems are programmed to drop a precise one picoliter circular droplet, the wells forming as a result of TRX folding fit myriads of droplets snuggly, thus controlling bleed and penetration by preventing the ink from slipping deep into the paper structure, as encountered in the uncoated paper (oval marks in Fig. 8a). Better-defined edges are possibly produced by (1) the masking effects of folded TRX associated with the coverage of paper fiber and micro-voids, and (2) the dendritic fibrillary ends slipping into the void (Fig. 8c (inset), thus defined as the trailing limit of the ink. The phenomenon closely attests to the micro-tonano canal effects that significantly improve the metal-flattened paper printability, demonstrating the altered capillary action attributed to TRX coating. The effective control of TRX over the inkjet droplet imbibition dynamics is also reflected in reducing cross-sectional ink penetration from $70 \%$ to $60 \%$ of an A4 substrate thickness.

Unless folded, TRX masking evidence via electron microscopy was impossible because of TRX-fiber adhesion, which made delineation impossible. Commercial paper containing inorganic filler was examined to elucidate further the TRX-substrate interaction leading to enhanced printability. 

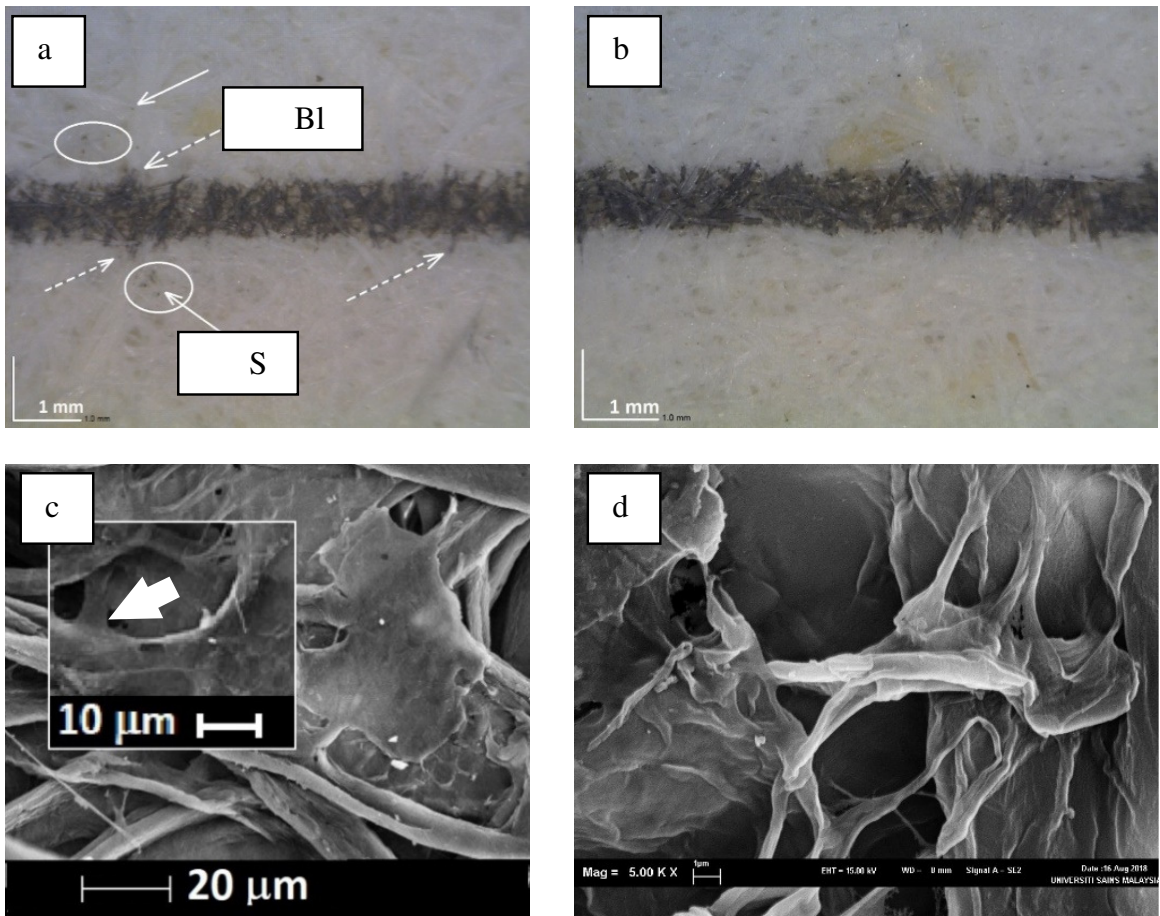

Figure 8: Stray and bleed (dashed arrows) on virgin pulp network (sample E) (a) without and (b) with a TRX coat. Close-up look at TRX cells on the substrate reveals (c) a patch of folded TRX, monolayer TRX slipping into void (inset, arrow) and (d) tangled cells

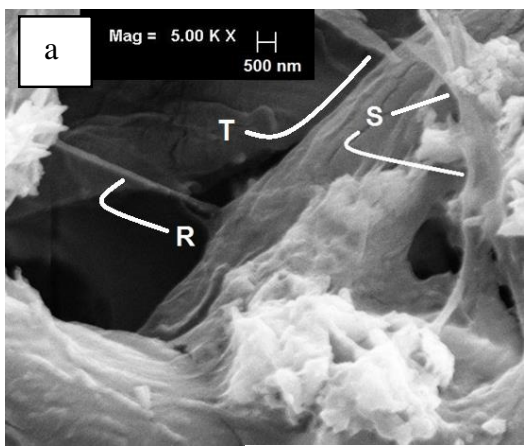

\begin{tabular}{|c|c|c|c|}
\hline & Element & Weight\% & Atomic\% \\
\hline & C & $93.35+1-0.70$ & 95.17 \\
\hline & 0 & $6.11+/-0.64$ & 4.67 \\
\hline & Si & $1.23+/-0.23$ & 0.54 \\
\hline & $\mathrm{Ca}$ & $0.07+/-0.13$ & 0.02 \\
\hline & & $-0.75+/-0.17$ & -0.40 \\
\hline & Tutals & 100.00 & 100.00 \\
\hline
\end{tabular}
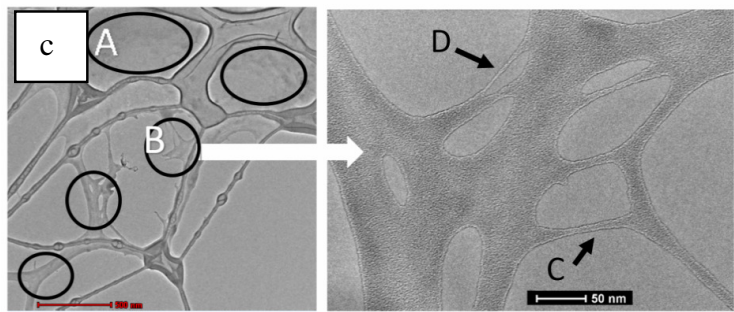

Figure 9: TRX coating formed (a) a canopy (S) atop inorganic fillers in commercial paper and capillary-like bridges (R). EDX revealed the cell as containing inorganics with (b) the mineral composition associated with

(c) area A of the isolated TRX rupturing to the structure on the right

\section{TRX-commercial A4 interaction}

On the surface of commercial A4 papers (Fig. 9a), coating cells formed a canopy (S) atop the protruding inorganic filler (Ca 22\%; C 22\%; O $56 \%$ by atomic percentages), hence assisting delineation between the coating cells and the paper substrate.

Prolonged electron charging of TRX cells, which resulted in web breakage ( $\mathrm{T}$ in Fig. 9c), revealed a soft translucent layer of $100 \mathrm{~nm}$ 
approximate thickness. In the form of a 60 -gsm handsheet, $100 \%$ TRX shows a TAPPI Opacity of $72 \pm 4 \%$.

The curling structure of TRX-cells forming a narrow bridge, denoted as $\mathrm{R}$ (Fig. 9a), is analogous to the capillary bridges. ${ }^{46}$ On surface voids, the coating cells were more likely to slip into the voids, leading to the occurrence of a dendritic covering posed by the fibrillary ends of the cells, similar to the fibrillary ends encountered on virgin pulp substrate (Fig. 8c - inset). The dendritic ends defined the trails for inks to flow, too minute to appear to the naked eye and, thus, the defined edges of the print. As the fibrillary ends landed above the surface micro-voids, capillary bridging occurred. The varying TRXcells widths limit further ink penetration through the microporous substrate and eliminate the print from appearing overleaf.

\section{Nano-enabled substrate}

Observing paper surface phenomena was possible due to the nanometre scale thickness of the TRX cells of impossible to define shapes. Together with its fibrillary ends, the nano-enabled substrate had undergone at least one of these five effects: (1) canopy or "loose-masking" effect (arising from TRX-inorganics incomplete adhesion), (2) capillary bridging of surface microvoids, (3) TRX-fiber masking (single layer, folded or tangled), (4) masking of shallow surface voids and (5) the dendritic masking of microvoids by the nano-fibrillary ends. These are thus far the spotted mechanisms of paper surface detailing that formed highly selective trails, guiding the ink to precisely land on paper surface as intended in the computer-programmed images.

The main factor for the stray reduction was spotted by elemental mapping via HighResolution Transmission Electron Microscope hyphenated with Energy Dispersive Analysis of $\mathrm{X}$-ray (HRTEM/EDAX), revealing the presence of the nano-minerals: silicon, sodium, and calcium (Fig. 9b). The minuscule size of the nano-minerals had plausibly also confined the print line of the programmed images, thus offering well-defined edges and less stray, which could not be possibly achieved with the conventional inorganic filler. The phenomenon is brought about by the high surface energy, typical of nanoscale particles. Their high fiber affinity was observed in a similar vein to that reported by Nallathambi and coauthors. ${ }^{47}$
The canopy effect of TRX coatings on the inorganic filler may offer a solution for nanoparticle migration to food - which is the current concern with paper-based ${ }^{25}$ food packaging. At the present stage of knowledge, TRX positive enhancement of inkjet printability implies the possibility of availing human-friendly nano-enabled papers with extra compatibility to inkjet printing. The substrate would then be a valuable complement to the booming demand for paper packaging and inkjet printing.

\section{CONCLUSION}

The translucent nano-meter thick TRX-cells delaminated from EFB microfibers engendered paper surface detailing by a set of distinct mechanisms evident from improved printability of selected papers. Several mechanisms engendering the nano-enabled paper surface were canopy or "loose masking" effects on inorganic fillers and surface voids, capillary bridging, masking of the fiber surface, and dendritic mask slipping into surface voids. The TRX-cells applied as paper coats could improve print uniformity, coverage and reduce print bleed and the quantifiable stray of inkjet prints, thus demonstrating their potential to be used in nano-enabled precision printing.

ACKNOWLEDGMENT: The research is funded by The Ministry of Higher Education (MOHE) of Malaysia through Fundamental Research Grant Scheme FRGS/1/2019/STG07/USM/02/8, supporting the United Nations' Sustainable Development Goal 12, Responsible Production and Consumption.

\section{REFERENCES}

1 M. S. Khan, G. Thouas, W. Shen, G. Whyte and G. Garnier, Anal. Chem., 82, 4158 (2010), https://doi.org/10.1021/ac100341n

2 T. Woods, Appita J., 70, 308 (2017)

3 Y. Z. Zhang, Y. Wang, T. Cheng, W. Y. Lai, H. Pang et al., Chem. Soc. Rev., 44, 5181 (2015), https://doi.org/10.1039/C5CS00174A

4 M. Hubbe and R. Gill, BioResources, 11, 2886 (2016),

https://ojs.cnr.ncsu.edu/index.php/BioRes/article/view/ BioRes_11_1_2886_Hubbe_Gill_Review_Fillers_Pap ermaking/4242

5 R. A. Baan, Inhal. Toxicol., 19, 213 (2007), https://doi.org/10.1080/08958370701497903

6 E. Bastarache, 2015, http://digitalfire.com/4sight/hazards/ceramic_hazard_ti tanium_dioxide_339.html 
7 International Agency for Research on Cancer, "IARC Monographs on the Evaluation of Carcinogenic Risks to Humans", 2010, vol. 93, pp. 1-452

8 X. Chen, X. Qian and X. An, BioResources, 6, 2435

(2011),

https://ojs.cnr.ncsu.edu/index.php/BioRes/article/view/ BioRes_06_3_2435_Chen_QA_Using_CaCO3_Whisk ers_Filler/1009

9 J. A. F. Gamelas, A. F. Lourenco, M. Xavier and P. J. Ferreira, Chem. Eng. Res. Des., 92, 2425 (2014), https://doi.org/10.1016/j.cherd.2014.02.003

10 Y. Sang, M. McQuaid and P. Engekzos, BioResources, $\quad 7, \quad 354 \quad$ (2012), https://ojs.cnr.ncsu.edu/index.php/BioRes/article/view/ BioRes_07_1_0354_Sang_ME_Prefloc_PCC_High_Fi ller_/1311

11 P. A. Gane, M. Buri, R. V. Blum and B. Karth, U.S. Patent No. 7,638,017, Washington, DC, U.S., 2009

12 IMA-NA, Industrial Minerals Association - North America, https://www.imana.org/page/what_is_calcium_carb

13 E. J. Plumstead, U.S. Patent No. 2,178,606, Washington, DC: U.S., 1939

14 J. Jurišová, V. Danielik, P. Fellner, M. Králik and T. Foltinovič, Acta Chim. Slov., 12, 14 (2019)

15 Y. Wang, R. Chen, X. Zhou, S. Jin, Y. Zhang et al., J. Nanosci. Nanotechnol., 20, 3610 (2020), https://doi.org/10.1166/jnn.2020.17423

16 LabChem Inc., Calcium Carbonate Safety Data Sheet (LC12690), 2016, http://www.labchem.com/tools/msds/LC12690.pdf

17 Di-Corp Inc., 2017, https://www.dicorp.com/public/download/documents/9954

18 OSHA, Occupational Safety and Health Administration, Materials Safety Data Sheet Calcium Carbonate, 2020, Calcium Carbonate, http://www.osha.gov/chemicaldata/220

19 F. A. Morsy, S. M. El-Sheikh and A. Barhoum, $\begin{array}{lllll}\text { Arab. J. Chem., 12, } 1186 \quad \text { (2019), } & \text { 12, }\end{array}$ https://doi.org/10.1016/j.arabjc.2014.11.032

20 J. Shen, Z. Song, X. Qian, F. Yang and F. Kong, $\begin{array}{llll}\text { BioResources, } & 5, & 1328 & \text { (2010), }\end{array}$ https://ojs.cnr.ncsu.edu/index.php/BioRes/article/view/ BioRes_05_3_1328_Shen_SQYK_Nanofillers_Paper making_Editorial/637

21 G. Li, L. Liang, J. Yang, L. Zeng, Z. Xie et al., Nanotoxicology, $\quad \mathbf{1 2}, \quad 571 \quad$ (2018), https://doi.org/10.1080/17435390.2018.1465606

22 USRAN, US Research Nanomaterials, 2016, www.us-nano.com

23 C. Ostiguy, G. Lapointe, L. Menard, Y. Cloutier, M. Trottier et al., IRSST Studies and Research Projects Report R470, 2006

24 M. Asztemborska, M. Jakubiak, R. Steborowski, E. Chajduk and G. Bystrzejewska-Piotrowska, Water Air Soil Poll., 229, 208 (2018), https://doi.org/10.1007/s11270-018-3852-8
25 L. Sherman, Appita J., 71, 181 (2018)

26 C. L. Soskolne and L. E. Sieswerda, Chronic Diseases and Injuries in Canada, 29, 2 (2010)

27 M. Pettersen, Master's Thesis, Chalmers University of Technology, 2011

28 R. Allan, Appita J., 1 (2019)

29 J. Shen and X. Qian, BioResources, 7, 1385 (2012), https://ojs.cnr.ncsu.edu/index.php/BioRes/article/view/ BioRes_07_2_1385_Shen_Qian_Surface_Filling_Edit orial $/ 1418$

30 A. Barhoum, H. Rahier, R. E. Abou-Zaied, M. Rehan, T. Dufour et al., ACS Appl. Mater. Interfaces, 6, 2734 (2014), https://doi.org/10.1021/am405278j

31 N. H. Kamaluddin, Master's Thesis, Universiti Sains Malaysia, Malaysia, 2012

32 IUCN, International Union for Conservation of Nature, IUCN Issues Brief, Switzerland, 2018, https://www.iucn.org/resources/issues-briefs/palm-oiland-biodiversity

33 United Plantations Berhad, 2020, Sustainability Report, https://unitedplantations.com/wpcontent/uploads/2021/03/Sustainability_Report_2020.p df

A. Treerutkuarkul, 2021, https://www.bangkokpost.com/business/2048875/maki ng-palm-oil-more-sustainable

35 N. H. Kamaluddin, A. Ghazali and W. D. Wanrosli, BioResources, $\quad 7, \quad 3425 \quad$ (2012), https://ojs.cnr.ncsu.edu/index.php/BioRes/article/view/ BioRes_07_3_3425_Kamaludin_GW_Fines_Reinforce Alkaline_Fruit_Bunch/1607

${ }^{36}$ S. Kaza, L. Yao, P. Bhada-Tata and F. Van Woerden, Urban Development Series World Bank Group, Washington, 2018

37 TAPPI Test Method T211, Ash in Wood, pulp, paper and paperboard: combustion at $525^{\circ} \mathrm{C},(2007)$, https://tappi.org/content/sarg/t211.pdf

38 P. Fardim, "Paper and Surface Chemistry - Part 2 Coating and Printability", 2019, https://www.tappi.org/content\%5CJournal\%5C2002\% 5CTJ\%5C09sep02\%5CFardim2_Eng.pdf

39 J. Bangera, "Laser Toner Cartridge: What's Inside?",

2019 ,

https://blog.inkjetwholesale.com.au/printer-

education/laser-toner-cartridge-whats-inside/

40 ISO/IEC, International Organization for Standardization/International Electrotechnical Commission, 2017, ISO/IEC 24790:2017(en)

41 Y. Dong, B. Wang, J. Hairui, W. Zhu, Z. Long et al., BioResources, 15, $1397 \quad$ (2020), https://ojs.cnr.ncsu.edu/index.php/BioRes/article/view/ BioRes_15_1_1397_Dong_Papermaking_Conditions_I nk_Absorption/7401

42 Iggesund Paperboard, 2019, https://www.iggesund.com/paperboard-referencemanual.aspx 
43 S. P. Singh, Bioresources, 3, 2, 503-516 (2008), https://ojs.cnr.ncsu.edu/index.php/BioRes/article/view/ BioRes_03_2_0503_Singh_PaperSmoothnessEvaluati on/198

44 R. Dorey, in "Ceramic Thick Films for MEMS and Microdevices", 2012,

https://www.sciencedirect.com/topics/engineering/drop let-size

45 B. M. Cummins, R. Chintapatla, F. S. Ligler and G. M. Walker, Anal. Chem., 89, 4377 (2017), https://doi.org/10.1021/acs.analchem.6b04717
46 F. J. Schmied, C. Teichert, L. Kappel, U. Hirn, W. Bauer et al., Sci. Rep., 3, 2432 (2013), https://doi.org/10.1038/srep02432

47 G. Nallathambia, T. Ramachandran, V. Rajendran and R. Palanivelu, Mater. Res., 14, 552 (2011), https://doi.org/10.1590/S1516-14392011005000086 